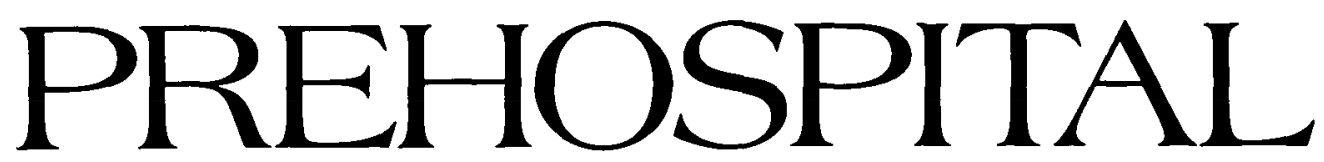

\title{
and
}
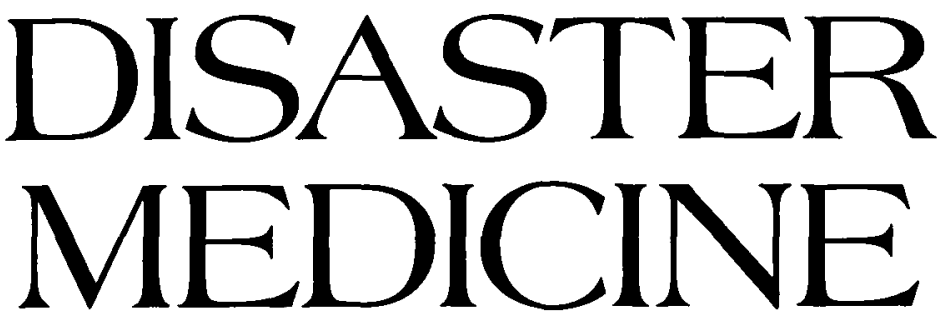

Médecine Pré-Hospitalière et Médecine de Catastrophe Medicina Prehospitalária y de Catástrofes 病院にかかる前の処置亡 災害医療

Abstracts of Scientific and Invited Papers 6th Asia-Pacific Conference on

\section{Disaster Medicine}

Fukuoka, Japan

18-22 February 2002 


\section{Abstracts of Scientific and Invited Papers for 6th Asia-Pacific Conference on Disaster Medicine}

Fukuoka, Japan

18-22 February 2002

Table of Contents

\section{Keynote Addresses}

Globalization of Emergency Response to Humanitarian Crises ...................S1

Tadateru Konoé

Disaster Management Evaluation. The Current Status of the Standardised Protocol

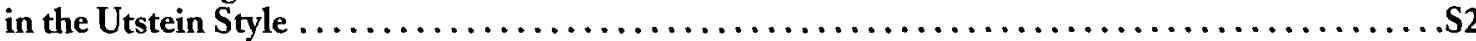

Knut Ole Sundnes; Marvin L. Birnbaum

\section{Future of Disaster Medicine}

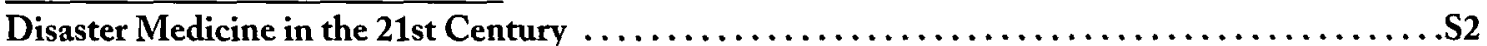

Jeffrey Arnold, MD, FACEP, FAAEM

Disaster Medicine in the 21st Century: Issues and Challenges $\ldots \ldots \ldots \ldots \ldots \ldots \ldots \ldots \ldots \ldots . \mathbf{S 3}$

Kendall Ho, MD FRCPC

Disaster Medicine in the 21st Century: Taiwan in the Asia-Pacific $\ldots \ldots \ldots \ldots \ldots \ldots \ldots \ldots . . .63$

Lee-Min Wang

Disaster Medicine in the 21st Century

V. Anantharaman

\section{Disaster Preparedness}

Effects of Emergency Medical Services System Design on Initial Response and

Treatment of Disaster Patients $\ldots \ldots \ldots \ldots \ldots \ldots \ldots \ldots \ldots \ldots \ldots \ldots \ldots \ldots \ldots \ldots . . .64$

Jerry Overton; Steve Murphy

Establishing Health Epidemiology for Chemical Spills in Mining Industries .............S5

Jinky Leilanie Lu

Controlling Environmental Pollution Disaster from Industrial Emissions $\ldots \ldots \ldots \ldots \ldots \ldots \ldots$.S5

Maria Gilda Plata

Disaster Surveillance Approaches for Technological Hazards in Semiconductor Industries .......S5

Jonalyn Del Prado

"Staffordshire" System for Nuclear, Chemical, and Biological Decontamination . . . . . . . . . .S6

Roger C. Thayne

Hazardous Materials Emergencies: Decontamination in the USA ....................

Howard Levitin, MD, FACEP

Decontamination in the Field and in Emergency Departments in Hazardous Material (CBR)

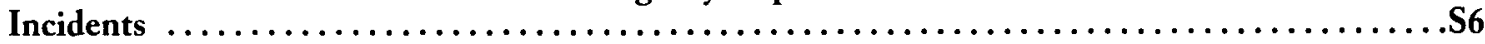

Eric W. Williams

A Pragmatic Approach to Effective Pre-clinical Mass Decontamination ................S7

Chris Green

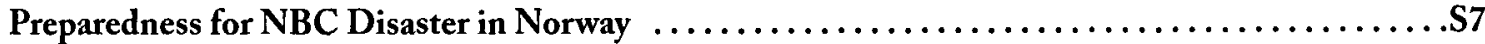

Jan Karlsen

Planning to Reduce the Risk of Mass Casualties in Large-Crowd Events $\ldots \ldots \ldots \ldots \ldots \ldots . . .67$

Eric W. Williams

High School Students Assist Hospital in Mass Casualties Events

Bianca Lederman, $M D$; Nurith Fertel, RN, BA 
Using National Health Insurance Claim Format as the Main Frame of Database Structure

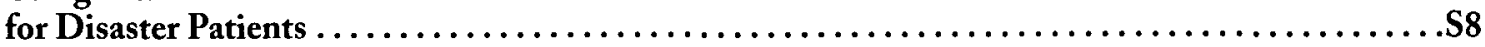

Jeffrey Tsai; Chen-Yue Lin; Sheng-Li Chang; Fub-Yuan Shib

Role and Challenges of Japan's ODA for Emergencies in the Asia-Pacific Region ............S8

Osamu Kunï; Toshimitsu Ishigure; Yukio Isbida

Preparedness for Biological Disasters in Japan and the United States . . . . . . . . . . . . . .S9

Raymond $A$. Zilinskas

Community-Based Disaster Preparedness in Bangladesh Coastal Area . . . . . . . . . . . . . . .S9

Seishi Takamura; Akira Miyata; Sunao Asai; Yukiya Saito; Akira Nakata

Drastic Reforms of the Emergency Medical Response System to Radiological Emergencies

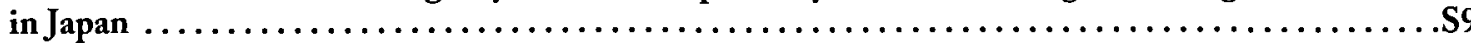

Kazubiko Maekawa, $M D$; Tatsuya Kinugasa, $M D$

Disaster Medical Care Management and JICA's International Cooperation . . . . . . . . . . . .S10

Yuji Okazaki; Mitsutaka Hoshi; Nozomu Yamashita; Hitosbi Otomo

Cooperation of JICA for Strengthening a Disaster Medicine System . . . . . . . . . . . . S10

Mai Okada; Tsutomu Nakano; Michiyo Hashiguchi; Hideaki Kasabara; Koichi Sasadate; Yuji Okazaki

Japan's Disaster Relief and Japan Overseas Cooperation Volunteers (JOCV) . . . . . . . . . . . .S10

Ken Hasegawa; Koichi Sasadate; Mitsutaka Hosbi; Katsunari Harada

Use of Landing Service and Parking Areas for Helicopter Emergency Medical Service (HEMS) $\quad$.S11

Hideki Honda; Takabisa Kawashima; Nobuo Kaku

Medical Preparedness and Response: A Disaster Management Plan for Hospitals in India ......S11

Dr. Dolly Matbew

Disaster Management in India: Current Initiatives

Colonal Rajive Kobli

Israeli Hospital Preparedness for Disasters

LTC. G. Neuman; MAJ. I. Hendler, MAJ. M. Golan; LTC. G. Margalit; MAJ. D. Naor;

MAJ. M. Pres; COL. B. Tadmor

The Israeli Doctrine for Hospital Management of Mass Toxicological Incident

MAJ. I. Hendler; Lion Poles; LTC. G. Neuman; I. Tur-Kaspa; COL. B. Tadomor

The Development of NDMAT in Taiwan . . . . . . . . . . . . . . . . . . . . . .

Ming-Che Tsai; Chih-Hsien Chi; Chia-Chang Chuang; Hsin-Ling Lee

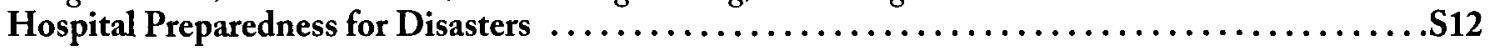

Chung-Liang Shib; Ting-I Lai; Wen-Jone Chen

Preparedness for Mass Gatherings in the XVIII Winter Olympic Games in Nagano . . . . . . . . S13

Hiroshi Okudera

Usage Review of Global Maritime Distress and Safety System .......................

Isao Nakajima; Yongguo Zhao; Hiroshi Juzoji; Hirotaka Kato; Sadaki Inokuchi; Atsushi Nakajima

\section{Damage}

Terrorist Bombing Disasters: Implications for Emergency Department Response . . . . . . ....S13 Jeffrey Arnold, MD, FACEP, FAAEM

World Trade Center Tragedy: An Economic Analysis Using YPLL (Years of Potential Life Lost). .S14 Zafar Ahmed; Azhar Abdul Aziz

Forced Displacement: A Disaster in Colombia-The Case of Antioquia! $\ldots \ldots \ldots \ldots \ldots \ldots . . S 14$

Emilio Huertas Arias

Survey and Cost-Analysis of Injuries in the Ji Ji Earthquake in Taiwan $\ldots \ldots \ldots \ldots \ldots \ldots . . .514$

Wen-Ta Cbiu

Morbidity Following Chi-Chi Earthquake in Taiwan $\ldots \ldots \ldots \ldots \ldots \ldots \ldots \ldots \ldots \ldots \ldots \ldots$. 15

Wan-Ching Lien, MD; Fub-Yuan Shib, MD; Matthew H-M Ma, MD, PbD; Wen-Jone Chen, MD, PhD

Prediction of the Devastating Effects of a Typhoon based on Logistic Regression . . . . . . . . . . S15

Fub-Yuan Shih, MD; Matthew H-M Ma, MD, PhD; Kuang-Jui Chang, MD; Wen-Jone Chen, $M D, P b D$

\section{Evaluation/Response}

What Have We Learned, So Far?

Marvin L. Birnbaum, $M D, P b D$

A Systems Approach to Triage and Management of a Large-scale Bioterrorist Event

Frederick M. Burkle, Jr., $M D, M P H$ 
Evaluation of Disaster Response in the Tottori-Ken Seibu Earthquake, 2000: A Preliminary

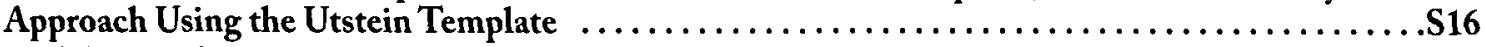

Yukibiro Watob, $M D, P b D$; Shinichi Nakayama, $M D, P b D$; Shin Ishibara, $M D, P b D$; Sakayu Terashi, $R N$

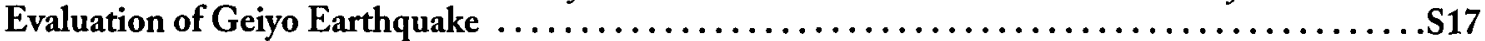

Katsubiko Ibara MD; Takubiro Hotta, MD; Hajime Ogawa, MD; Tatsuo Matsuoka, MD;

Katsushige Goami Me

Mortality from the Chi-Chi Earthquake in Taiwan

Chiung-Yuan Hsu, MD; Fub-Yuan Sbih, MD; Wan-Ching Lien, MD; Matthew Huei Ming, MD, PbD;

Wen-Jone Chen, $M D, P b D$

Problems in Disaster Rescue Work in Taiwan

Kuang-Jui Chang, MD; Fub-Yuan Shih, MD; Ting-I Lai, MD; Matthew H-M Ma, MD, PhD;

Wen-Jone Chen, $M D, P b D$

The Medical Needs, Public Health, and Living Environment following the

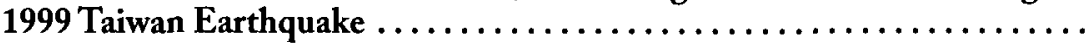

Keiji Nakata; Norimasa Seo; Hisayoshi Kondo; Yuichi Koido; Yasubiro Yamamoto

Hanshin-Awaji Earthquake and Medical Response: An Overview ..................S18

Hiroshi Tanaka

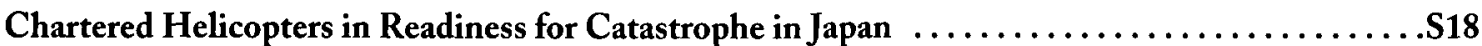

Masabiro Takiguchi, MD

Disaster Relief following the Earthquake in Western India: Basic Health Care Activity with ERU

Operated by the Japanese Red Cross Society $\ldots \ldots \ldots \ldots \ldots \ldots \ldots \ldots \ldots \ldots \ldots \ldots . . .619$

Seishi Takamura; Akira Miyata; Sunao Asai; Wakako Takashima; Hidenobu Matsukane

Honduras Disaster Relief Operation of Japan Self-Defense Forces in November 1998

Koichi Shincbi; Eishu Nakamura; Hiroshi Abe; Hiroshi Hosoai; Hisayoshi Amma; Takashi Akima;

Hiroomi Hashizume

Japan Disaster Relief Medical Team Activities following the Earthquake in India

Yasushi Shimada

The Report of the Japanese Red Cross Society International Medical Relief ERU during the

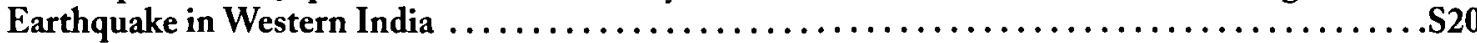

Koji Sato, MD; Kiyosbi Isbikawa; Nobuyuki Suzuki; Mitsuki Tanaka; Kazuyoshi Yamaguchi

Lessons of Earthquakes in Russia and Abroad in XXI Century . ....................S20

Sergey Fedorovich Goncharov; Victor Nicholaevich Preobrajensky

Department of International Medical Relief at Nagoya Daini Red

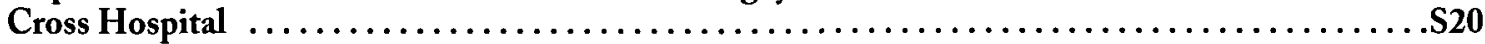

Mitsuki Tanaka; Kiyoshi Ishikawa, MD; Koji Sato, MD; Nobuyuki Suzuki, MD; Asako Akatsuka;

Tomoko Sakai

Aerotransportation and Telemedicine of Injured Patients from Remote Volcanic Islands

Makoto Mitsusada; Itaru Osaka; Nobunori Koga; Tatsue Yamazaki

Problems of Immediate Medical Care at Taipei Community Hospitals During

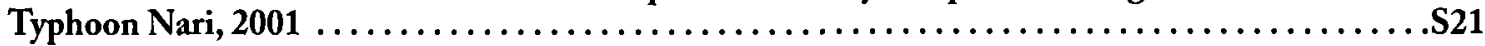

Wen-Chu Cbiang, MD; Fub-Yuan Sbib, MD; Kuang-Jui Chang, MD; Wen-Jone Chen, $M D, P b D$

Public Health Response to 1998 Flood in Bangladesh-Key Lessons Learned

Dr. SK MD Mamunur Rabman Malik; Dr. Qudsia Huda

Relief Activities by the ICRC for the Complex Disaster in Sudan

Makiko Kiriyama, RN; Takami Takahashi, RN; Shinichiro Suzaki, MD

Ex-Post Evaluation of Japan Disaster Relief Assistance ........................S22

Koichi Sasadate; Masahiro Hashizume; Hisayoshi Kondo; Norimasa Seo; Tatsuo Ono; Katsunari Harada;

Mitsutaka Hosbi; Takasbi Mizuno; Yukio Ishida; Yuji Okazaki

Evaluation of Health Disaster Management During the Mozambique Flood in 2000

Hisayoshi Kondo; Norimasa Seo; Masahiro Hashizume; Kouichi Sasadate; Yasubiro Yamamoto

Evaluation of the Activities of the Japan Disaster Relief (JDR) Medical Team for Flood

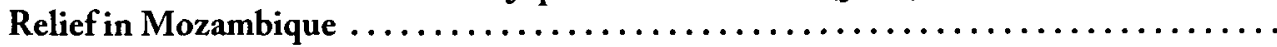

Norimasa Seo; Hisayoshi Kondo; Masabiro Hashizume; Kouicbi Sasadate; Yasubiro Yamamoto

Emergency Medical Management for a Mass Gathering Event at a Fireworks Festival in

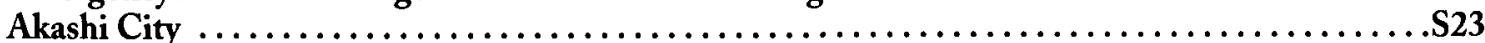

Noboru Ishii; Tatsuro Kai; Yukibiro Wato; Kazubiro Yoshimoto

Complex Emergencies and Humanitarian Assistance $\ldots \ldots \ldots \ldots \ldots \ldots \ldots \ldots \ldots \ldots . . .623$

Etsuko Kita

Difficulties in Relief Activities for Refugees

Tosbibaru Makishima 
The ICRC Hospital in Dili, East Timor during Sub-Acute Phase after the September

1999 Conflict

Nobuyuki Suzuki

Evaluation of the Response to the Crisis in South Valkan

Akira Miyata

Forgotten Emergencies in Sudan and Sierra Leone

Miki Takahara

\section{Patient/Medical Care}

Analysis of 372 Patients with Crush Syndrome Caused by the Hanshin-Awaji Earthquake ......S25

Jun Oda

Diagnosis, Treatment and Pathophysiology of the Crush Syndrome $\ldots \ldots \ldots \ldots \ldots \ldots \ldots \ldots$.S25

Junichiro Yokota

Radiographic Imaging and Histological Findings of Crush Syndrome

Masasbi Kishi, Tetsuro Nishimura

Clinical Presentations of Typical and Atypical Crush Syndrome

Yasuki Nakata; Mitsuo Ohnish; Takeshi Sbimazu; Toshibaru Yosbioka; Hisashi Sugimoto

Long-Term Physical Outcome of Patients Who Suffered Crush Syndrome: Prognostic IndicatorsS26

Tetsuya Matsuoka

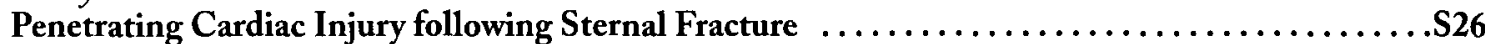

Francis Fu Sheng Wu; Chi-Wen Juan; Fang-Chu Chen; Sai-Kit Ho; Yao-Ru Hu; Tzu-Hui Tung

The Effects on the Central Nervous System Induced by Tetrodotoxin Poisoning . . .........S27

Francis Fu Sheng Wu; Cbi-Wen Juan; Pang-Chi Lai; Kuo-Chou Cheng; Chia-Ju Wu; Hsiu-Hui Hou;

Tetsuya Matsuoka

Six Years Experience with Telemedicine in an Emergency Department in Taiwan

Lee-Min Wang, MD; Hong-Chang Lo, MD; Chen-Hsen Lee, MD; Dab-Dian Tang; Pi-Chin Yu;

Low-Tone Ho, $M D$

Covering Disasters: A Look at Disaster News Reporting in the Philippine Media during 2001 ...S28

Lirio Racho Luyun

Monitoring of Cabinet X-Ray Users

Jose Lauro Muangi Llamas

Traditional Surgical Practice and Adverse Health Outcomes Among Refugees in Tanzania

Osamu Kunii; Yasuo Tanaka; Lewis Alyson; Naoki Ito; Susumu Wakai

\section{Education and Training}

Meeting New Challenges in Disaster Medicine Education

Frederick $M$. Burkle, Jr., MD, $M P H$

Introduction of European Master in Disaster Medicine (EMDM)

F. Della Corte; F. La Mura; M. Debacker; H. Delooz

Education and Training in Disaster Medicine

Azhar Abdul Aziz

Top-Off Exercise in Washington, DC

Masato Homma, MD; Yasubiro Otomo, MD; Hiroshi Henmi, MD; Takashi Arai, MD

Training Hospital Staff to Cope with a Chemical Mass Casualty Event (CMCE)

Bianca Lederman, MD; Nurith Fertel, RN, BA

Night Field Drill for Disaster Medical Assistance Team (DMAT)

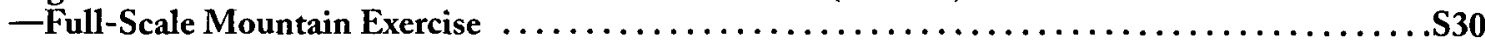

Chia-Chang Chuang; Cbib-Hsien Cbi; Hung-Jung Lin; Yuang-Lung Yen; Ming-Che Tsai

Regional Training Course for Radiation Emergency Medicine in Asia ...................S31

Hisayoshi Kondo; Toshiyasu Hirama; Naoyuki Anzai; Misao Hachiya; Makoto Akashi

International Urban Search and Rescue Team Training: The Stress and Medical Complaints of

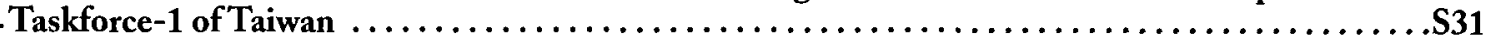

Patrick Chow-In Ko, MD; Chang-Ping Su, MD; Matthew Huei-Ming Ma, MD, PbD; Fang-Yue Lin, MD, PhD

\section{Legal Aspects of Disaster Medicine}

The Right to Health of the Disaster Stricken

S. William Gunn, MD, DSc(Hon), FRCSC 


\section{Psychosocial Aspects of Disaster Medicine}

Psychological Correction and Psychotherapy of Post-Traumatic Stress Disorder in Children and

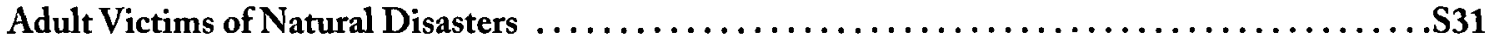

Igor Briazgounov; Inna Larkova; Alexander Michailov; Maria Abalakina

Psychiatric Assistance to the Population of the Chechen Republic during

Anti-Terror Operations

Victor Nicholaevich Preobrajensky; Valery Petrovich Kohanov

Gendered Battlefields in Mindanao: Health Social Science and Disaster Medicine

Reynaldo Hapan Imperial; Laufred Ilagan Hernandez

\section{Organizations}

The World Association for Disaster and Emergency Medicine (WADEM): From Mainz to

Melbourne..

Frank Archer

Problems of International Cooperation at the Interaction Level in the Network of

WHO Collaborating Centres ...

Gennady Victorovich Kipor; Sergey Fedorovich Goncharov

"Action Plans"-Declaration of the 5th APCDM (30 September 2000)

Wayne Greene, PhD; Diana Ericson; Kendall Ho, MD FRCPC

Disaster Management and Coordination of the International Red Cross Movement ...

Yasuo Tanaka 